\title{
Lead User Adaptation within Information Systems: Human Behavior as a Predictor of Enterprise Resource Planning Systems Implementation Outcomes
}

\author{
Amos Allie \\ Case Western Reserve University \\ Shola Ajiboye \\ Case Western Reserve University
}

\begin{abstract}
Human actions invoke the user-centered framework of technology. We present a novel approach to understanding systems behavior that comprises human interaction within Enterprise Resource Planning (ERP) systems space. We use the theories of Reasoned Action and Planned Behavior (TPB) to examine how and to what extent Lead Users utilize specific patterns to influence implementation outcomes. Using a mixed methods approach for our inquiry and an analysis based on a structural equation model (SEM), our initial findings extend the study on Lead User Adaptation. The results and implications are discussed.
\end{abstract}

\section{INTRODUCTION}

The complexity of software implementation within firms makes it very challenging for implementing organizations to fully grasp the multi-level dynamics of human behavior. This study relies on user knowledge sharing (UKS) and user herd behavior (UHB) to introduce a model of Lead User adaptation within systems and to underscore its robust impact on implementation outcomes. We address the merits of utilizing knowledge sharing and herd behavior to influence successful outcomes within postimplementation. We submit that higher cultivation of appropriate Lead User knowledge sharing could lead to a higher success rate of ERP Implementation outcomes while mitigating fewer failure rates. A distinct understanding of the root causes of implementation failures, using the Lead User perspective, will help minimize capital loss in both private and public sectors while mitigating against an organization's predisposition for risk (Asprion, Schneider et al. 2018).

Lead Users' behavior, knowledge sharing, and herd behavior play a role in the implementation outcome. Lead Users are defined as innovative team members who evolve while developing requisite skills to adapt, rather than adopt, lingering issues and present a fixed pattern that works for ongoing challenging scenarios. Although constructivist frameworks (Pollock and Williams 2009) lay out a plausible explanation for end user behavioral patterns within implementation, they do not account for specific actions and reactions to outcomes, especially outcomes that have unique consequences on specific deployment dimensions from the lead user perspective. A more contextual design seeks to understand the circumstances in which Lead Users evolve and predict resolutions. Little attention is paid to examining how these resolutions are transferred to other teams with similar challenges while perfecting 
less successful scenarios. Similarly, little attention is focused on how failing scenarios are diagnosed by Lead Users and what solutions are specifically attractive to each scenario.

Earlier studies identify the significant value added within implementations as (1) organizational and technological rubrics- which involves the radicalness of technology, (2) processes improvement through innovation and (3) an organization's propensity to redefine innovation in its current state (Karim, Somers et al. 2007). Our study contributes a fourth factor: the unique capacity of the Lead Users to predict outcomes while preventing deployment failures. We rely on Planned Behavior Theory (PBT) and Theory of Reasoned Action to understand the phenomenon as stipulated by our model.

Although knowledge sharing and herd behavior have been extensively used in information system literature, missing in the literature is a unique perspective in measuring the utilization of knowledge sharing and herd behavior by Lead Users and Lead Users' influences on implementation outcome. We postulate that Lead Users, through effective utilization of innovation, are changing the structural dynamics within implementation process space while utilizing unique skillsets like imitated behaviors, that need to be accurately measured. At the least, a conceptual model is needed, that positions Lead Users as a focal point in understanding implementation outcomes and replicating productive outcomes that impact the firms' bottom line (Mun and Hwang 2003). The model needs to synthesize concepts from both practice and theoretical approaches and provides both theoretical and practical implications that are viable and significant to a firm's deployment performance.

Using two-step structural equation modeling, our proposed hypotheses guides future discourse as to whether the Lead Users' behavior has significant effects on implementation outcomes. We utilize contextual factors such as knowledge sharing by external team members as a mediator. The independent variables comprise knowledge acquisition, herd behavior, solution knowledge importation, and lead user knowledge integration by internal team members. Lead user performance and implementation outcomes are operationalized as dependent variables. The study seeks to understand the relationships between Lead Users and knowledge acquisition, and knowledge sharing and knowledge integration, within implementation space. We ask: To what extent do Lead Users acquire, share, and integrate projectrelevant knowledge? How and to what extent do Lead Users' knowledge acquisition, knowledge sharing and knowledge integration influence Enterprise Resource Planning (ERP) Implementation outcome. Finally, how do herd behavior and knowledge sharing influence successful system use at the postadoptive stage of software implementation?

\section{THEORETICAL FRAMING AND REVIEW OF LITERATURE}

We review the literature on key components of the study including the revolving relationship between the cognitive and rational influence of knowledge sharing and herd behavior on Lead Users. While user perceived ease of use and usefulness have been well covered in the literature, yet there is a gap about how to measure outcomes of imitated behavior and knowledge sharing and the mediating effect on postimplementation success. To identify these predictors of success in ERP innovation, firms continuously strive to identify alternative methods that will ensure legitimate, sustained success. In effect, the emergence of Lead Users within ERP implementation could not be timelier. Given learned lessons from failed and successful scenarios, we argue that 'Super Users' have not only adopted but also assimilated significantly over a period. Super users and Lead Users are used interchangeably in this study to define those users whose skills and learning propensity supersede other users within the same implementation. Assumptions on assimilations will be directly tested by our hypothesized model.

The complexity of the post-implementation environment equips users with significant learning and adaptation capabilities. However, in replicating successful patterns, these parameters are further challenged by intrinsic bounded rationality (Lai, Lai et al. 2016). Although the technology acceptance model significantly dissects innovation usefulness and perceived ease of use, there is still evidence of human rational insight influencing successful post-implementation patterns (Allie 2017). Lai and others (2016) argue that bounded rationality plays an interrupting role in executive decision making. The argument further builds on users' ability to effectuate satisfying outcomes rather than cognitive design.

Journal of Organizational Psychology Vol. 19(2) 2019 
There is a constraining dynamic at play when users are faced with the pressure of making swift decisions that have direct impact on outcomes. Such decisions are rather guided by functional success rather than cognitive structured outcome. The theory of rational choice posits that humans have the propensity to generally be rational and act in ways that are incrementally rational than optimal (Simon 1972).

Nikolaeva (2014) shares insights on how organizational imitation limits cognitive herd behavior of Lead Users. The study also demonstrates how organizations 'imitate to succeed' and 'imitate the majority'. The premise of the argument further delineates the capacity of organizations to initiate herd behavior with a focused objective to succeed. However, our study improves on the initial premise by advancing the lens of the argument to circle-up on Lead Users. Organizations' initial herd behavior to impact successful outcomes are led and initiated by experienced super users. The extent to which super users imitate and initiate ideas impacts success in diverse dimensions like user acceptance test, integrated tests, and Plus/Delta Tests. This further substantiates the premise that herd behavior is a cognitive heuristic (Nikolaeva 2014).

Given the complexity of ERP deployment within post-implementation environment, Lead Users with various teams have recognized the essence and impact of herd behavior. Social imitation, for example, allows Lead Users to embed within successful teams that are undergoing similar patterns. These embedded individuals observe, imitate, and make use of newly learned skills from successful teams within implementing teams (Allie 2017). Such practices have been known to have successful outcomes on less successful teams. Additional benefit is that a firm's knowledge sharing capacity impacts its competitive advantage (Kearns \& Sabherwal, 2006).

The ability of ERP implementing organizations to share knowledge to a significant extent depends on Lead Users' ability to adapt and assimilate such knowledge capabilities. Such a knowledge base is usually divided into tacit and explicit knowledge sharing (Shao, Feng et al. 2012). While explicit knowledge follows the paradigms of formal concepts and scripted formats, tacit knowledge is highly contextual and reflects user expertise drawn from multiple years of experience derived from repetitive action. The emergence of tacit knowledge emanates from a user's ambition to learn, adapt and successfully assimilate. Since tacit knowledge is drawn from multiple layers of human behavior, there remains a gap in how such knowledge sharing has been thoroughly measured to explain its derived outcome on ERP implementations. Our research attempts to fill this gap by explaining the extensive and complex impact of tacit knowledge sharing on various levels of human behavior and interactions. In addition, Jeppesena and Laursenb (2009) argue that Lead Users in product development share requisite knowledge that has relevant impact on other users. The premise of the study is centered around specific capabilities of users to share unique knowledge base characteristics that impact successful outcomes. Where such attributes impact teams, individual users' impact ranges from the creation of new products to transferring of such knowledge to failing teams.

There is a distinction between knowledge sharing among Lead Users in product development as defined by Jeppesena and Laursenb (2009) and knowledge sharing as depicted by Lead Users in ERP implementation. We made attempt to identify the direct relationship of knowledge sharing and ERP implementation outcome. Our aim is to improve on existing knowledge about this relationship by using both herd behavior and knowledge sharing in understanding the direct transaction impact on ERP success. This is in addition, to the examination of how human elements like knowledge sharing and herd behavior are influenced by bounded rationality.

\section{Operationalization of Constructs}

A total of eight constructs were used to develop our hypothesized model as presented in diagram 1. The constructs include three predictors, one mediator, and two control variables to measure two dependent variables. The scales used in this study were adopted from previous studies.

\section{Dependent Variables: Implementation Outcome and Lead User Performance}

An 8-item scale was used to measure ERP analyst performance. Measurement focused on the extent a person conforms to his or her role (Lynch, Patrick 1999). A 7-item scale was used to measure post- 
implementation deployment implementation outcome. We measured internal and external users and client ratings of the quality of the prototype and process flow generated during post-implementation deployment (Majchrzak, Ann, Cynthia M. Beath, and Ricardio A. Lim 2005).

\section{Independent Variables: Lead User Knowledge Integration, Herd Behavior and Knowledge Importation}

A 5-item scale was used to measure knowledge integration. The scale measured the perceived importance of a variety of information systems technical knowledge items that are included in deployment, to the extent that they impact implementation outcomes through the perspective of the user (Lee, Denis M.S., Eileen M. Truth, and Douglas Farwell 1995). A 5-item modified scale was used to measure knowledge importation. The scale measured the increase in the intensity of knowledge flow within teams from other successful patterns. The flow includes attracting solution-oriented knowledge and skill that would yield net added value within the team with a projected effect on entire deployment (Collins, Christopher J. and Ken G. Smith 2006) A 5-item scale was used to measure herd behavior regardingthe extent to which users act the same way or adopt similar behaviors as other users around them, often ignoring their own feelings in the process. This behavior often involves users using the actions of others as a guide to successful outcomes or imitating others to correctly accomplish a task (Banerjee 1992).

\section{Mediating Variable: Knowledge Sharing}

A 6-item scale measured knowledge sharing. The scale measured the degree of one's positive feelings and willingness about sharing one's knowledge with others either within or outside of the team (Bock, Gee-Woo, Young-Gul Kim, and Robert W. Zmud 2005).

\section{Control Variables: Resource Level and Experience}

We included two theoretically relevant covariates or controls: 'Resource Level' and 'Experience' in order to control for other identified variables. Due to the unchanging nature of control variables, they allow the relationship between the variables being tested to be better understood.

\section{HYPOTHESES DEVELOPMENT}

\section{The Logic of Hypotheses}

Diffusion researchers have argued that innovation, system design and social systems as defined by human capital, influence implementation outcomes (Rogers 2003). The key offshoot of such interactions are innovation attributes. In contrast, some researchers have focused on Lead User characteristics as the most effective method for evaluating the innovation process flow (Hassan 2008). This level of innovativeness is simply defined by the magnitude to which Systems Analysts adapt a new idea that transforms them into lead innovators and subsequently Lead Users. Innovation to this extent is influenced by series of complex scenarios driven by multiple layers of specific actors.

Accordingly, we explain 'Lead User behavior' within ERP deployment, as the behavior held by users who directly or indirectly interact with the implementation environment and tools but have limited or no access to influence design decision making at the top of the leadership pyramid (Asprion, Schneider et al. 2018). The same is correct of ERP Analyst behavior. The crux of this study goes beyond lead user capacity. We utilize defined user-centered guidelines (Younous, Belaissaoui et al. 2018) to understand how lead user and ERP Analyst behavior can influence and indirectly control implementation outcomes without guidelines or rigid design frame work.

Our model hypothesizes that knowledge sharing has a positive effect on ERP Analyst performance implementation outcomes. Also, that knowledge sharing has a positive effect on lead user performance. We hypothesize that solution knowledge importation positively impacts lead user performance, ERP Analyst performance, and implementation outcomes. 
We hypothesize that team level innovativeness dampens the positive relationship between solution knowledge implementation and lead user performance. Finally, solution knowledge implementation strengthens the positive relationship between team level innovativeness and lead user performance.

\section{Direct Effect}

H1: Knowledge Sharing has a positive effect on Lead User Performance

H2: Herd Behavior has a negative effect on Lead User Knowledge Integration

H3: Solution Knowledge Importation Has a positive effect on Implementation Outcomes

H4: Lead User Knowledge integration has a positive effect on Implementation Outcomes

H5: Lead User Knowledge integration has a positive effect on Lead User Performance

\section{Mediated Effects}

H6: Lead User Knowledge Integration positively mediates the relationship between Solution Knowledge Importation and Implementation Outcomes

H7: Lead User Knowledge Integration Positively mediates the relationship between Herd Behavior and LU performance.

\section{METHOD}

\section{Mix Method: QUANT $\rightarrow$ Qual Strand}

We used a mixed method of QUANT-qual strand (Quantitative and Qualitative) to fully comprehend behavioral patterns within a unique research environment of Lead Users while using alternating sample sets to validate outcomes. The study puts greater emphasis on the quantitative inquiry with lesser emphasis on the qualitative study. We started with a quantitative approach using surveys with closedended questions. These surveys were distributed to 425 participants. Although we received $100 \%$ of the distributed surveys back only $97 \%$ was useful. $3 \%$ was either incomplete or inattentive responses.

To validate the results of our quantitative study, we conducted a qualitative study through embeddedness. We embedded within five Information Systems Implementing teams (HR, Supply Chain Management (SCM), Finance, Payroll, and Master Data Management MDM) for two weeks at eight hours per week in order to understand how and to what extent constructs like herd behavior influence user judgment while performing roles. With handwritten script from data collected, we used open and focused coding to identify patterns. From these coded patterns, categories were derived and subsequently, themes formed around common emerging subsets. Imitated behavior and knowledge sharing not only impact but influence systems outcomes. With an embedded case study methodology of this nature, we provide evidence-based means of integrating quantitative and qualitative methods into a single research study (Scholz and Tietje 2002, Yin 2003). The embedded case study design is an empirical form of inquiry appropriate for descriptive studies, where the goal is to describe the features, context, and process of a phenomenon and validate alternative studies. Roland W. Scholz (Year) suggests that "case is faceted or embedded in a conceptual grid" which allows identifying key components of human and environmental systems (Scholz and Tietje 2002).

By integrating these two studies we attempt to answer the study's research questions by utilizing a two-step structural equation modeling approach (Gerbing and Anderson 1988). In this approach, we conducted measurement model testing of our items and constructs. We then examined causal relationships among the constructs as outlined in Figure 1 for the purpose of hypotheses testing. 
The purpose of a measurement model is to provide an empirical estimate of each theoretical construct relevant to our study. Generally, we utilize factor analysis to estimate population-level (unobserved) structure underlying the variations of observed variables and their interrelationships. The validity of constructs was measured to evaluate whether the collected data aligns with the structure of the target construct, and to determine if the measures used have measured what they were supposed to measure. Model analyses were conducted through exploratory factor analysis and confirmatory factor analyses following the acceptable protocol used for data cleaning and determination of data adequacy.

\section{SAMPLE SIZE}

For the Quant strand, surveys were distributed to 425 participants. We utilize Lead Users and ERP Analysts within two (2) organizations in the United States. Although we received $100 \%$ of the distributed surveys back only $97 \%$ was useful. $3 \%$ was either incomplete or inattentive respondent. With a sample size of 416 after examining the data, this was enough for our model. According to (Hair, Anderson et al. 2010) one should have 5 to 10 times the number of indicators in a model to appropriately estimate the sample size.

For the Qual strand, we embedded within five Information Systems Implementing teams for 5 days (HR, Supply Chain Management (SCM), Finance, Payroll, and Master Data Management). We observed and took copious notes from implementers and users. Although we were not allowed to ask formal questions, we did ask questions where we thought the process, they were implementing was not quite clear. All notes were coded and analyzed with the emergence of themes that will be discussed in our result section. A good method for standardizing our sample size data is subject to item ratio. Studies have revealed that adequate sample size is partly determined by the nature of the data (Fabrigar et al., 1999; MacCallum, Widaman, Zhang, \& Hong, 1999). The following items were examined in the measurement model knowledge sharing (for external team members) $=5$ Items; herd behavior $=4$ Items; solution knowledge importation $=3$ Items; lead user's knowledge integration (for internal team members) $=3$ Items; lead user performance $=6$ Items; implementation outcomes $=3$ Items.

\section{ANALYSIS}

\section{Exploratory Factor Analysis (EFA)}

We used the exploratory factor analysis (EFA) as a useful construct (factor) technique for reducing many indicators to a more manageable set. It is particularly useful as a preliminary step in the absence of a sufficiently detailed theory about relations of the indicators to the underlying constructs (Churchill 1979). When researchers have little to no theoretical basis is to explain underlying factors of phenomena occurring in the real world, they use EFA to learn how variables work together, as well as to generate new theory. They do this by exploring latent factors that account for variations and interrelationships of these variables. Consequently, in this study, while we maintained a constant approach to our theoretical model, we also estimate the unknown structure of the data at the factor and item levels of analyses. Additionally, following Hinkin's, 1998 recommendation, we used the following criteria to determine the number and adequacy of factors for the EFA or the first step of the measurement model: eigenvalue greater than 1 and the scree test of the percentage of variance explained (Cattell 1966). Based on these criteria, a six (6) factor solution was identified.

We then examined the factor loadings and cross-loadings of the items. Items were retained if (a) they had high loadings on their primary factor (i.e., $1>.40$ ) and (b) they had low cross-loadings on any other factor (i.e., cross-loadings were less than half of their primary loadings;(Hinkin 1998). 


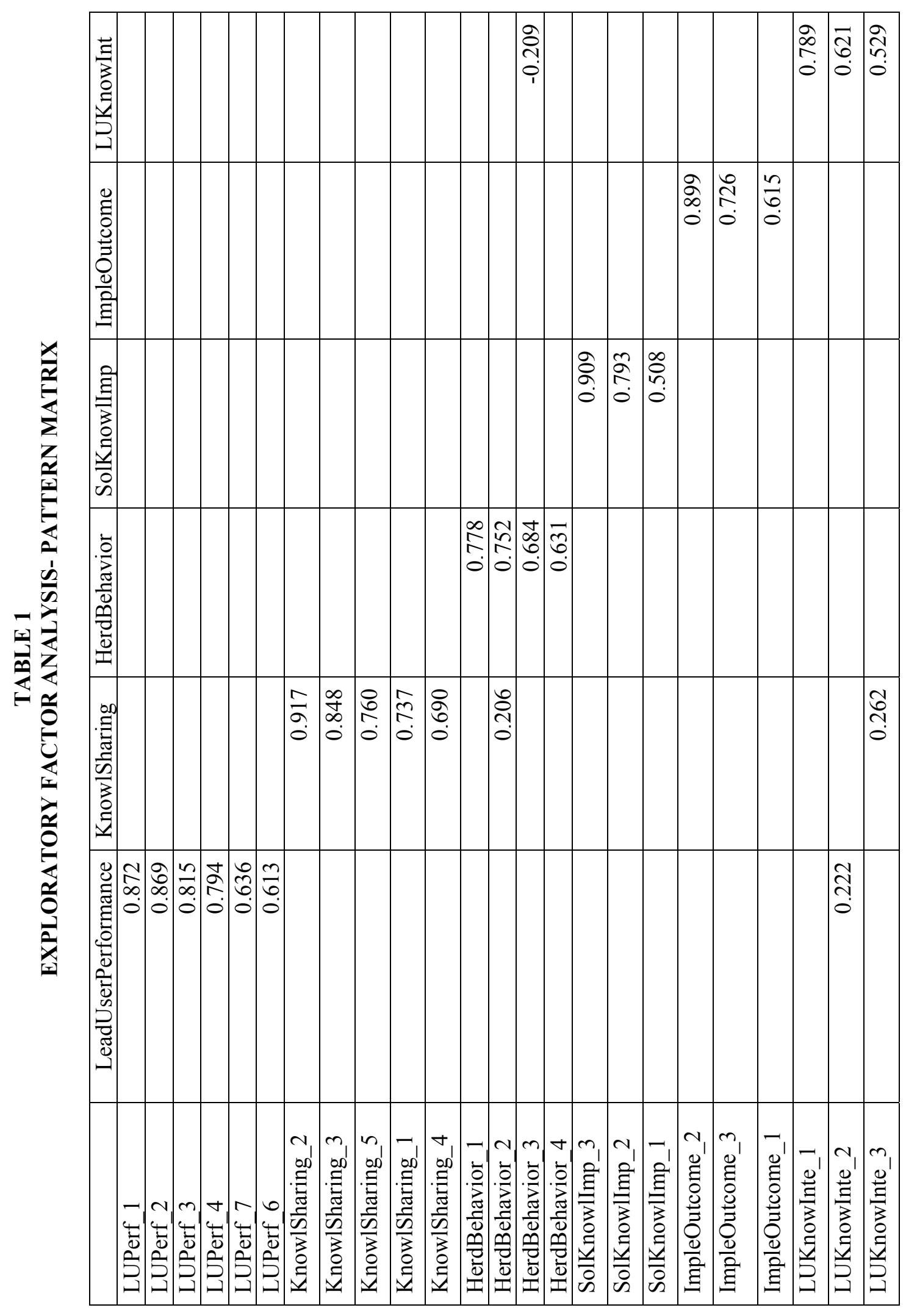

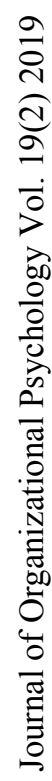




\section{COMMUNALITIES}

We examine Communalities and the cumulative percentage of variance using eigenvalue $>1$ rule. Although no fixed threshold exists, cumulative percentage of variance (criterion) meet the threshold (Hair, Anderson et al. 2010). The six factors demonstrate a cumulative percentage of variance of $\mathbf{6 8 . 1 3 \%}$ at eigenvalue $>1$.

\section{CONFIRMATORY FACTOR ANALYSIS (CFA)}

We tested the structures of our data through confirmatory factor analysis (CFA). The measurement model was estimated using AMOS (Analysis of Moment Structures) software v24.0, a non-covariancebased structural equation modeling technique using the maximum likelihood estimation approach. In this model, no uni-directional path was specified between any latent variable. Instead, a covariance model was estimated where each latent variable was correlated with every other latent variable. We also utilized CFA to illustrate and assess the convergent validity and discriminant validity factor structure of the observed correlations as theoretically framed in our model. Also, CFA was used to test our existing theory as hypothesized in our model. We determined that the model fits the data adequately. The "model fit" is determined by looking at various fit statistics and comparing them to acceptable standard or thresholds.

The psychometric properties of the six latent constructs involving 24 items were evaluated simultaneously in one confirmatory factor analysis (CFA). No items were trimmed in the measurement model. The sample size of 416 was deemed sufficient given low communalities (Hair, Anderson et al. 2010) and acceptable values on the Hoelter's Critical $\mathrm{N}$ test. Consequently, the model was expected to converge using maximum likelihood estimation.

\section{RESULTS}

All descriptive statistics result indicated that the exploratory factor analysis solution is adequate and acceptable (Table 1). First, we observed the Kaiser- Meyer-Olkin (KMO) statistic was 0.928. Second, Bartlett's Test of Sphericity was significant (chi square $=5091.192 \mathrm{df}=351, \mathrm{p}<0.001$ ) indicating enough Inter-correlations. Third, the communalities were all above 0.30 further confirming that each item shared some common variance with other items. Fourth, all measures of sampling adequacy across the diagonal of the anti-image matrix were above 0.70 , indicating that the data is appropriate for factoring. Fifth, an examination of the inter-item correlation matrix indicated approximately $80 \%$ of the correlations were over 0.30. Finally, an additional check for the appropriateness of the respective number of factors that were extracted was confirmed by examining reproduced correlation (and residuals). We found only 2 (1\%) non-redundant residuals with absolute values greater than 0.05 . We report the Cronbach test of reliability and consistency Alpha $=0.95$ and total variance explained- $=68.13 \%$ (Tables 2 and 3 ). 
FIGURE 1

PATH COEFFICIENT FOR HYPOTHESIZED MODEL

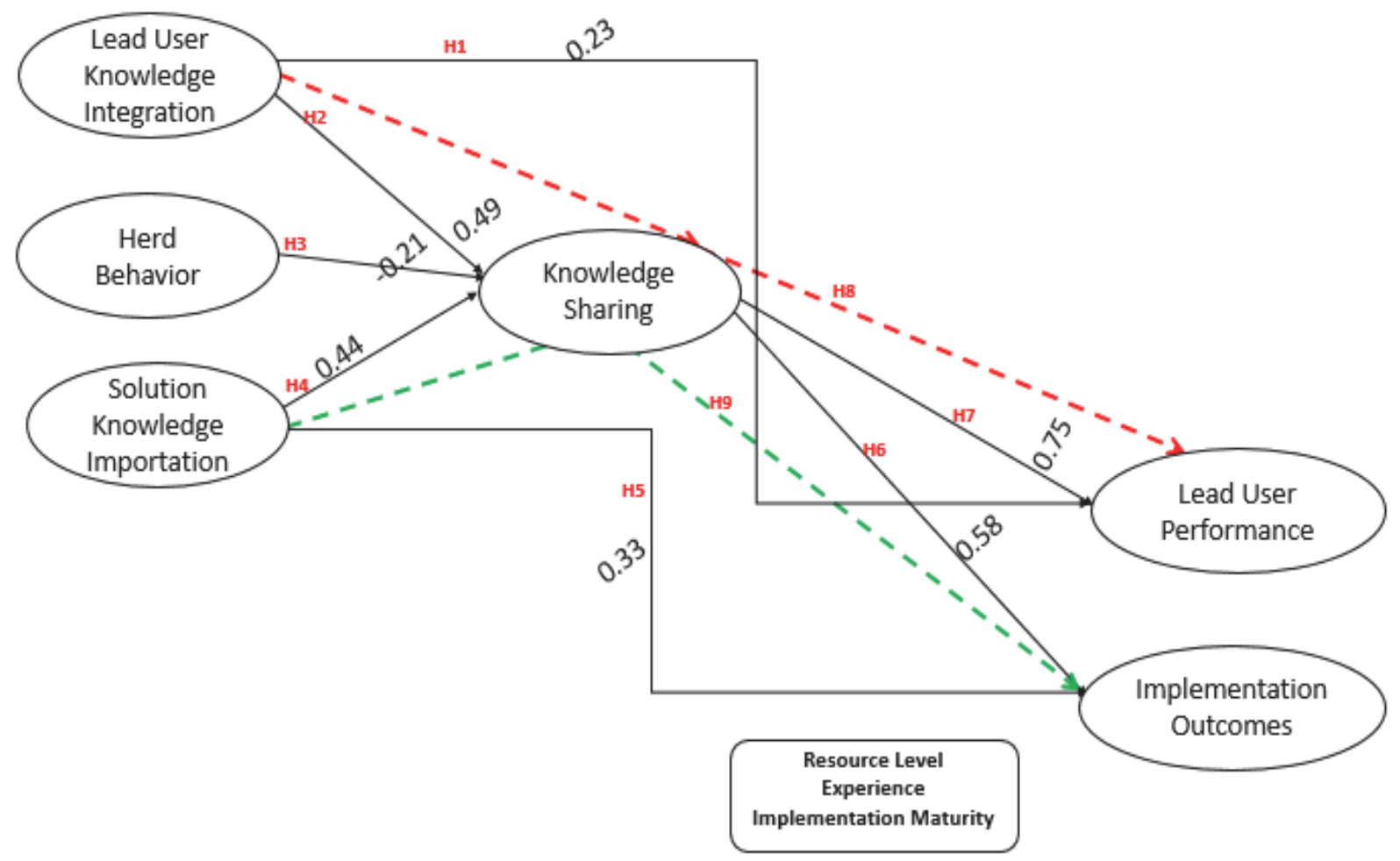

TABLE 2

CRONBACH'S ALPHA TEST OF CONSISTENCY AND RELIABILITY

\begin{tabular}{|l|c|r|r|r|r|}
\hline & $\begin{array}{c}\text { Scale } \\
\text { Mean }\end{array}$ & $\begin{array}{c}\text { Scale } \\
\text { Variance }\end{array}$ & $\begin{array}{c}\text { Corrected Item- } \\
\text { Total Correlation }\end{array}$ & $\begin{array}{c}\text { Squared } \\
\text { Multiple } \\
\text { Correlation }\end{array}$ & $\begin{array}{c}\text { Cronbach's } \\
\text { Alpha }\end{array}$ \\
\hline SolKnowlImp & 12.0338 & 12.755 & 0.867 & 0.865 & 0.916 \\
\hline HerdBevior & 12.5575 & 14.713 & 0.609 & 0.714 & 0.945 \\
\hline KnowlSharing & 12.1635 & 12.396 & 0.828 & 0.804 & 0.921 \\
\hline LUKnowInt & 12.3550 & 13.021 & 0.920 & 0.937 & 0.911 \\
\hline ImpleOutcome & 12.0733 & 12.934 & 0.848 & 0.794 & 0.918 \\
\hline LUPerf & 12.0294 & 12.304 & 0.807 & 0.774 & 0.925 \\
\hline
\end{tabular}




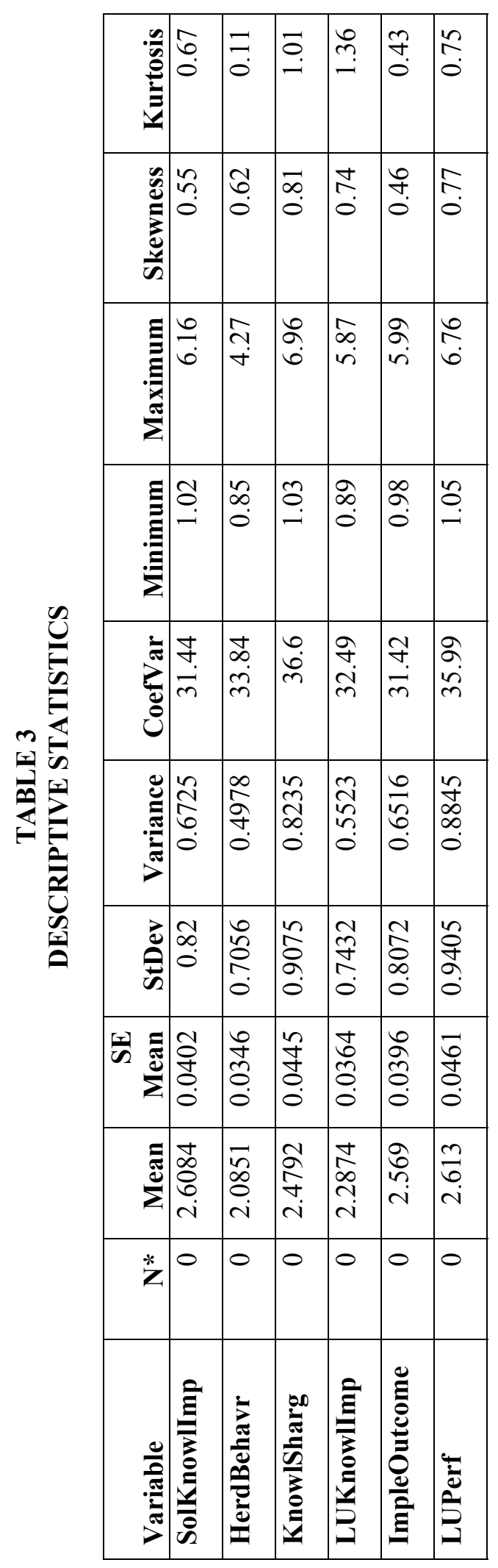

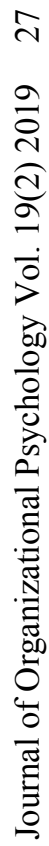


FIGURE 2

\section{GRUBBS TEST FOR OUTLIERS}

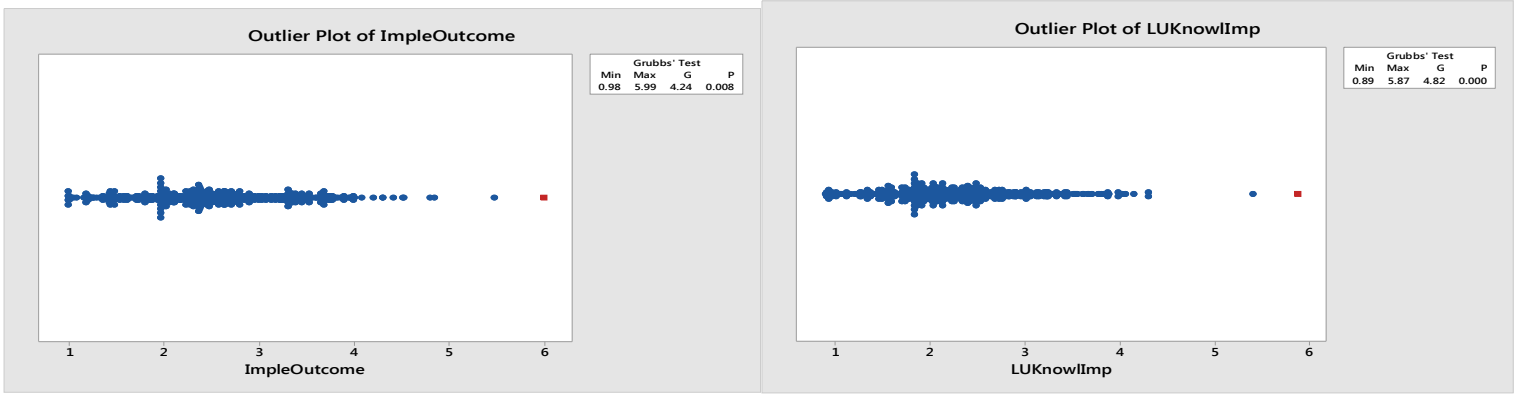

FIGURE 3

TEST FOR NORMALITY

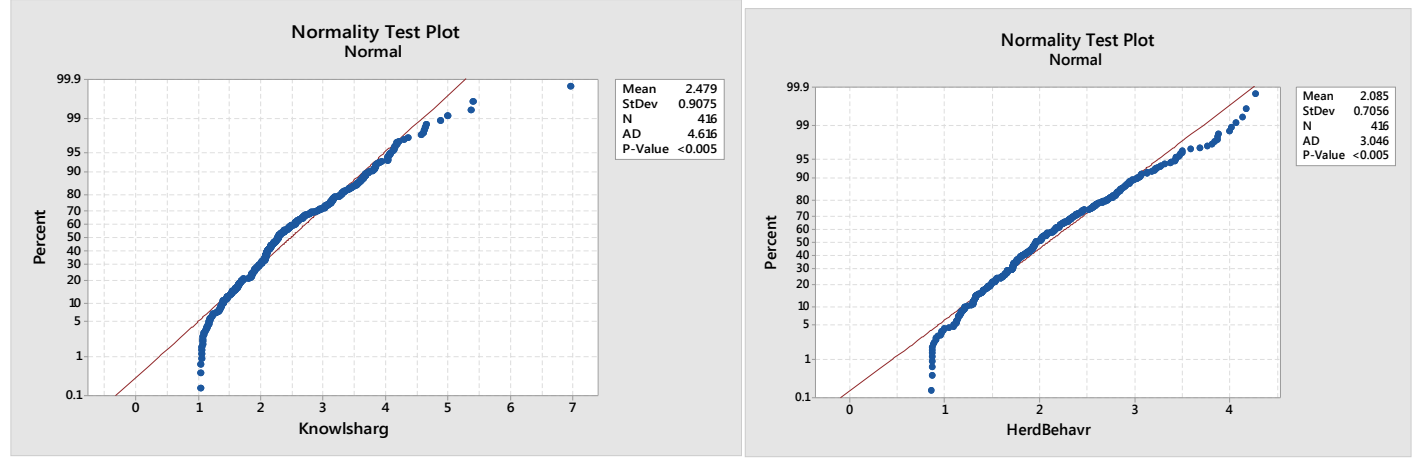

FIGURE 4

TEST FOR NORMALITY

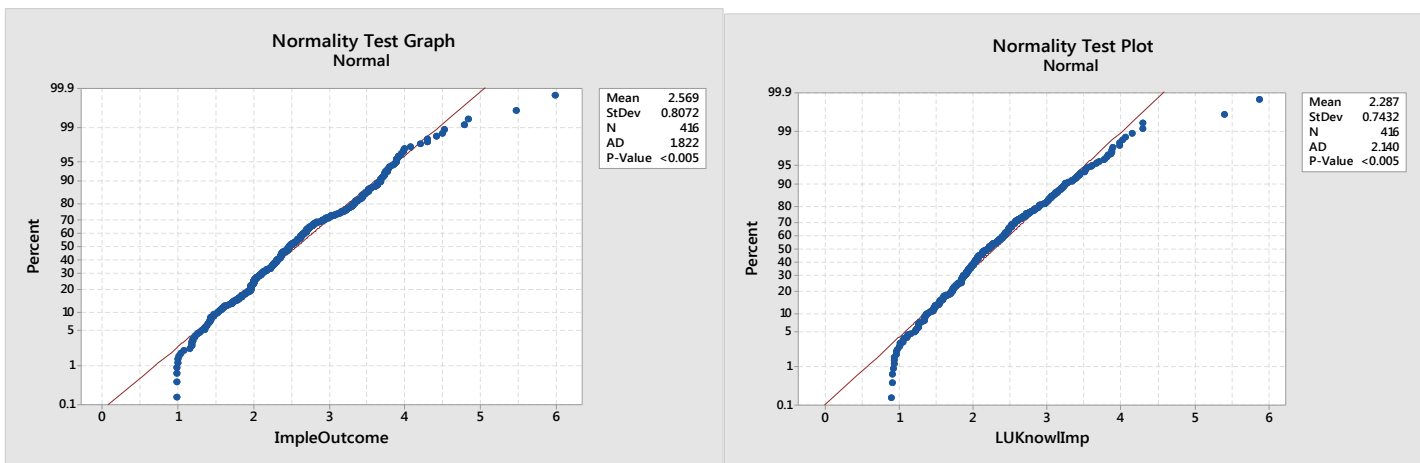


FIGURE 5

PROBABILITY TEST

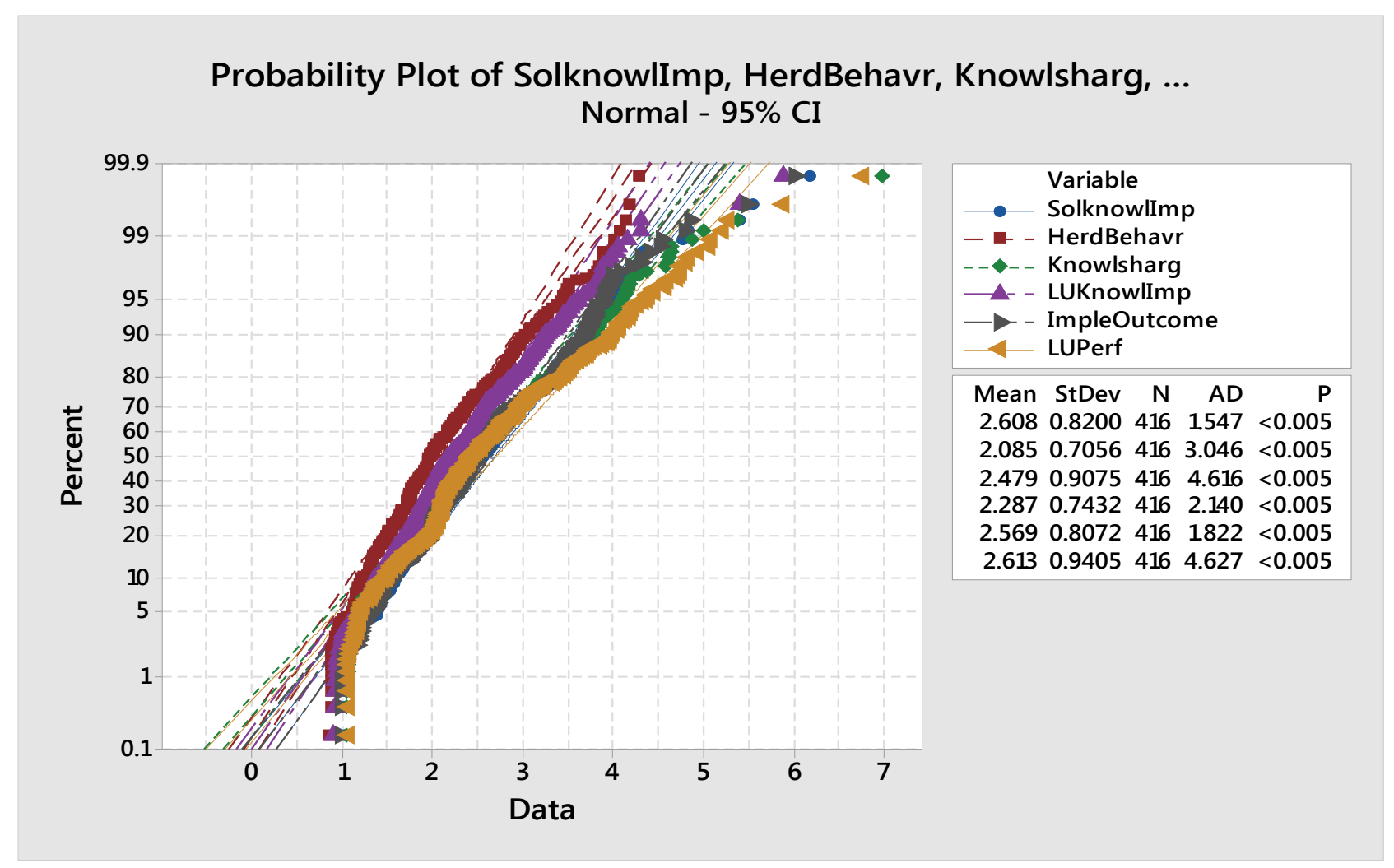

**The estimated percentiles are accurate only if the data follow the distribution closely.

TABLE 4

FACTOR CORRELATION

\begin{tabular}{|l|r|r|r|r|r|r|r|r|}
\hline \multicolumn{1}{|c|}{ Constructs } & Mean & $\begin{array}{c}\text { Std. } \\
\text { Deviation }\end{array}$ & SolKnowlImp & HerdBevior & KnowlSharing & LUKnowInt & ImpleOutcome & LUPerf \\
\hline SolKnowlImp & 2.6087 & 0.82031 & & & & & & \\
\hline HerdBevior & 2.0850 & 0.70594 & $.785^{* *}$ & & & & & \\
\hline KnowlSharing & 2.4790 & 0.90739 & $.701^{* *}$ & $.506^{* *}$ & & & & \\
\hline LUKnowInt & 2.2875 & 0.74316 & $.802^{* *}$ & $.484^{* *}$ & $.882^{* *}$ & & & \\
\hline ImpleOutcome & 2.5692 & 0.80759 & $.811^{* *}$ & $.559^{* *}$ & $.736^{* *}$ & $.864^{* *}$ & & \\
\hline LUPerf & 2.6130 & 0.94045 & $.697^{* *}$ & $.448^{* *}$ & $.779^{* *}$ & $.875^{* *}$ & $.722^{* *}$ & $* *$ \\
\hline
\end{tabular}


FIGURE 5

MEASUREMENT MODEL

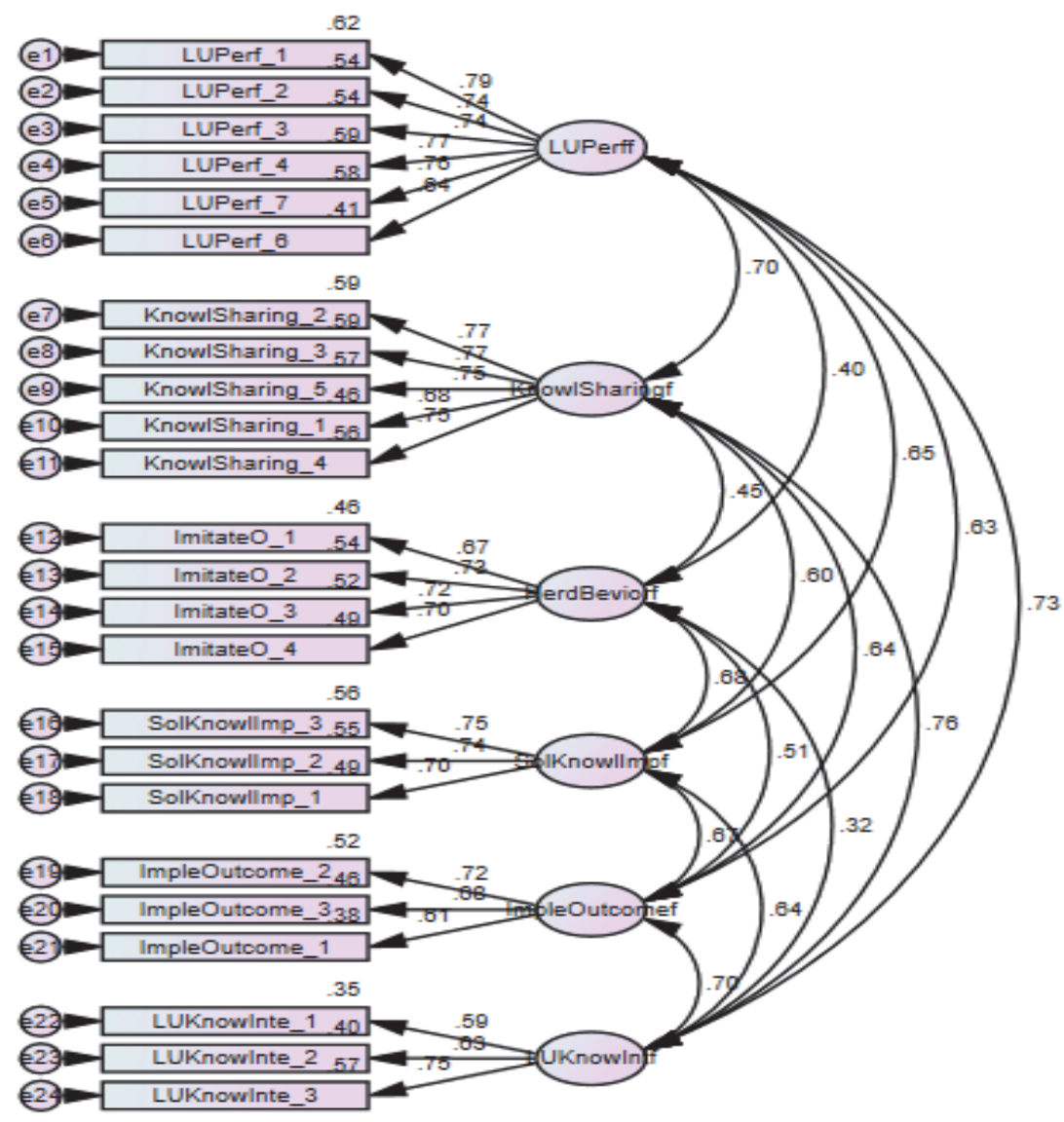

TABLE 5

MODEL VALIDITY MEASURES

\begin{tabular}{|c|c|c|c|c|c|c|c|c|c|}
\hline & CR & AVE & MSV & LUPerf & $\begin{array}{c}\text { KnowlS } \\
\text { haring }\end{array}$ & HerdBevior & $\begin{array}{c}\text { SolKnowl } \\
\text { Imp }\end{array}$ & $\begin{array}{c}\text { Imple } \\
\text { Outcome }\end{array}$ & $\begin{array}{l}\text { LU } \\
\text { KnowInt }\end{array}$ \\
\hline LUPerf & 0.879 & 0.548 & 0.534 & $\mathbf{0 . 7 4}$ & & & & & \\
\hline KnowISharing & 0.861 & 0.554 & 0.579 & 0.703 & $\mathbf{0 . 7 4 4}$ & & & & \\
\hline HerdBevior & 0.801 & 0.501 & 0.46 & 0.404 & 0.447 & $\mathbf{0 . 7 0 8}$ & & & \\
\hline SolKnowlImp & 0.775 & 0.535 & 0.46 & 0.649 & 0.597 & 0.678 & $\mathbf{0 . 7 3 1}$ & & \\
\hline ImpleOutcome & 0.712 & 0.553 & 0.494 & 0.633 & 0.644 & 0.513 & 0.67 & $\mathbf{0 . 7 7 3}$ & \\
\hline LUKnowInt & 0.797 & 0.537 & 0.579 & 0.731 & 0.761 & 0.324 & 0.643 & 0.703 & $\mathbf{0 . 7 6 1}$ \\
\hline
\end{tabular}




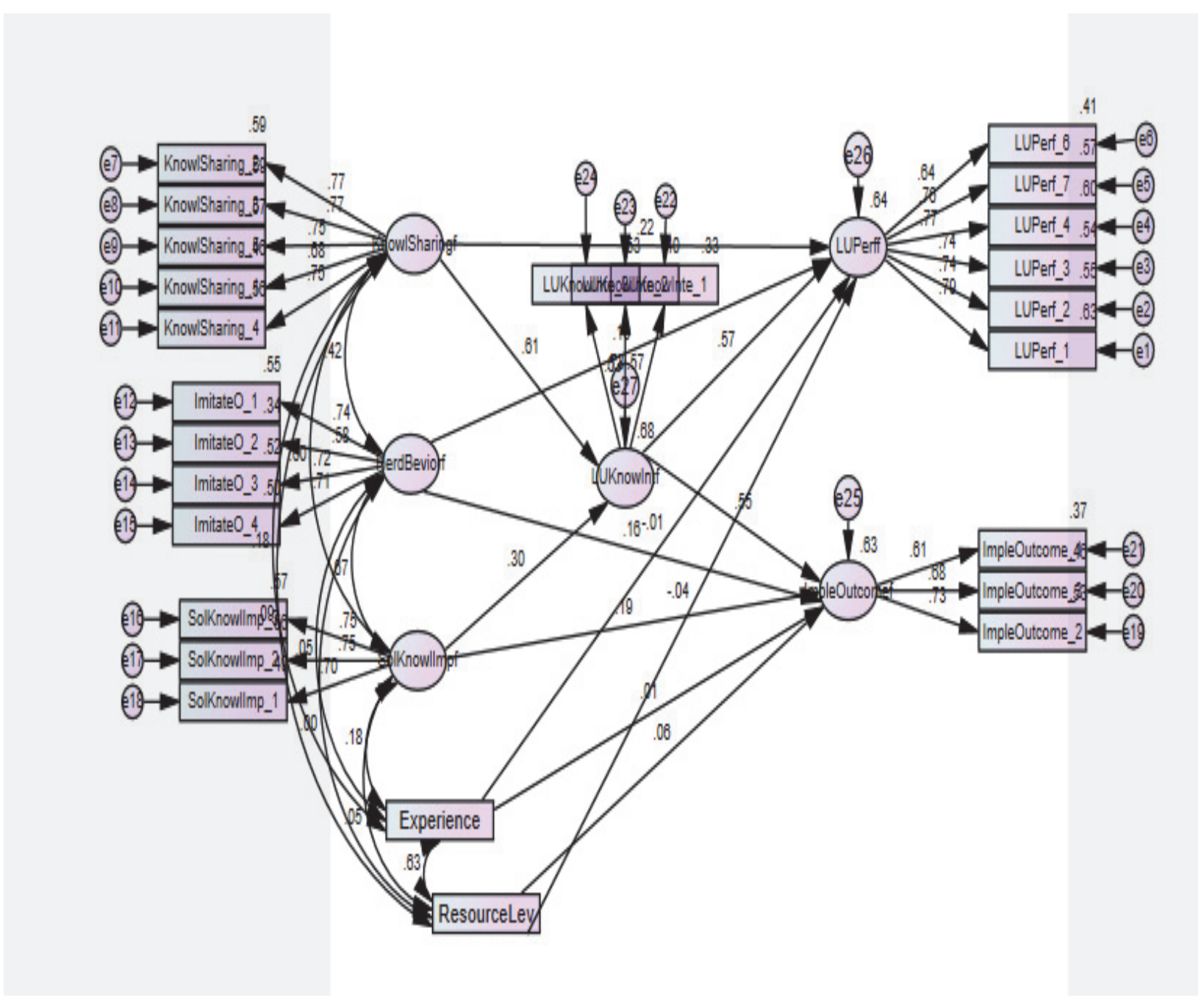

Based on Tables 9 and 10, the fit statistics of the measurement model, the structural equation model (SEM) and the mediation model indicate that the final model is a good fit for the study data. In testing the direct effect of our hypotheses 1, 2, 3, 4, 5, 6, and 7) we postulate a direct positive relationship between knowledge sharing and lead sharing performance, while herd behavior negatively impacts lead user knowledge integration. We also hypothesized that knowledge sharing positively impacts lead user knowledge integration while solution knowledge importation passively impacts implementation outcome. All hypotheses are strongly supported based on the significant relationships of regression supported on our model, as well as significant probability value. 
TABLE 6

MEASUREMENT MODEL $\rightarrow$ INITIAL MODEL FIT STATISTICS

\begin{tabular}{|l|l|l|c|r|}
\hline \multicolumn{1}{|c|}{ Measurement } & \multicolumn{1}{|c|}{ References } & \multicolumn{1}{c|}{ Threshold } & \multicolumn{1}{c|}{$\begin{array}{c}\text { Base Line } \\
\text { Model 1 }\end{array}$} & Interpretation \\
\hline Chi-square & & & 427.593 & \\
\hline CMIN & & & 237 & \\
\hline DF & & & & Excellent \\
\hline CMIN/DF & Hu \& Bentler, 1999 & 3 & $\mathbf{1 . 8 0 4}$ & \\
\hline PCLOSE & Hu \& Bentler, 1999 & $>0.05$ & 0.930 & Excellent \\
\hline RMSEA & Hu \& Bentler, 1999 & $<0.06$ & 0.044 & Excellent \\
\hline RMR & Hu \& Bentler, 1999 & $<0.08$ & 0.058 & Excellent \\
\hline SRMR & Hu \& Bentler, 1999 & $<0.08$ & 0.041 & Excellent \\
\hline & Joreskog \& Sorbom, 1984; & & & Excellent \\
GFI & Tanaka \& Huba, 1985 & $<0.95$ & 0.924 & Excellent \\
\hline AGFI & Joreskog \& Sorbom, 1984 & $<0.95$ & 0.904 & Excellent \\
\hline NCNFI & Bentler, 1990) & $>0.90$ & 0.907 & Excellent \\
\hline NFI & Bentler \& Bonett, 1980 & $<0.95$ & 0.958 & Excellent \\
\hline $\boldsymbol{C F I}$ & Hu \& Bentler, 1999 & $>0.90$ & 0.949 & Excellent \\
\hline TLI & Hu \& Bentler, 1999 & $>0.90$ & 0.893 & Excellent \\
\hline $\boldsymbol{R F I}$ & Hu \& Bentler, 1999 & $>0.70$ & &
\end{tabular}

TABLE 7

STRUCTURAL EQUATION MODEL- FIT STATISTICS

\begin{tabular}{|l|l|l|r|r|}
\hline \multicolumn{1}{|c|}{ Measurement } & \multicolumn{1}{|c|}{ References } & \multicolumn{1}{c|}{ Threshold } & \multicolumn{1}{c|}{$\begin{array}{c}\text { Base Line } \\
\text { Model 1 }\end{array}$} & Interpretation \\
\hline Chi-square & & & & \\
\hline CMIN & & & 480.570 & \\
\hline DF & & & 243 & \\
\hline CMIN/DF & Hu \& Bentler, 1999 & Between 1 and 3 & $\mathbf{1 . 9 7 8}$ & Excellent \\
\hline PCLOSE & Hu \& Bentler, 1999 & $>0.05$ & 0.639 & Excellent \\
\hline RMSEA & Hu \& Bentler, 1999 & $<0.06$ & 0.049 & Excellent \\
\hline RMR & Hu \& Bentler, 1999 & $<0.08$ & 0.058 & Excellent \\
\hline SRMR & Hu \& Bentler, 1999 & $<0.08$ & 0.051 & Excellent \\
\hline & Joreskog \& Sorbom, 1984; & & & Excellent \\
GFI & Tanaka \& Huba, 1985 & $<0.95$ & 0.916 & \\
\hline AGFI & Joreskog \& Sorbom, 1984 & $<0.95$ & 0.896 & Excellent \\
\hline NCNFI & Bentler, 1990) & $>0.90$ & 0.908 & Excellent \\
\hline NFI & Bentler \& Bonett, 1980 & $<0.95$ & 0.946 & Acceptable \\
\hline CFI & Hu \& Bentler, 1999 & $>0.90$ & 0.938 & Excellent \\
\hline TLI & Hu \& Bentler, 1999 & $>0.90$ & 0.882 & Excellent \\
\hline RFI & Hu \& Bentler, 1999 & $>0.70$ & & \\
\hline
\end{tabular}


FIGURE 8

MEDIATION MODEL INITIAL

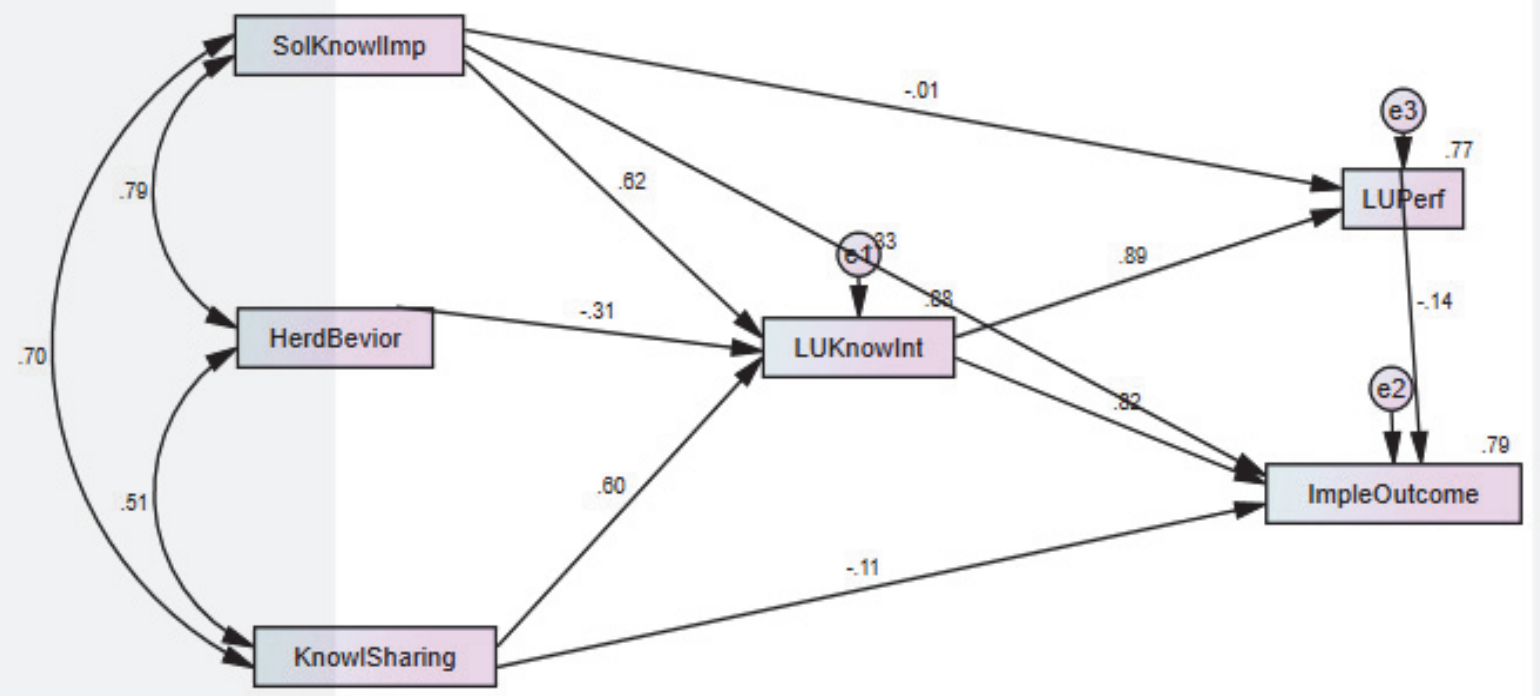

TABLE 9

MEDIATION MODEL FIT STATISTICS FINAL

\begin{tabular}{|c|c|c|c|c|}
\hline Measurement & References & Threshold & $\begin{array}{l}\text { Base Line } \\
\text { Model } 1\end{array}$ & Interpretation \\
\hline \multicolumn{5}{|l|}{ Chi-square } \\
\hline CMIN & & & 8.416 & \\
\hline DF & & & 3 & \\
\hline CMIN/DF & Hu \& Bentler, 1999 & Between 1 and 3 & 2.805 & Excellent \\
\hline PCLOSE & Hu \& Bentler, 1999 & $>0.05$ & 0.246 & Excellent \\
\hline RMSEA & Hu \& Bentler, 1999 & $<0.06$ & 0.066 & Excellent \\
\hline RMR & Hu \& Bentler, 1999 & $<0.08$ & 0.058 & Excellent \\
\hline SRMR & Hu \& Bentler, 1999 & $<0.08$ & 0.009 & Excellent \\
\hline GFI & $\begin{array}{l}\text { Joreskog \& Sorbom, 1984; } \\
\text { Tanaka \& Huba, } 1985\end{array}$ & $<0.95$ & 0.916 & Excellent \\
\hline AGFI & Joreskog \& Sorbom, 1984 & $<0.95$ & 0.896 & Excellent \\
\hline NCNFI & Bentler, 1990) & $>0.90$ & 0.896 & Excellent \\
\hline NFI & Bentler \& Bonett, 1980 & $<0.95$ & 0.997 & Excellent \\
\hline CFI & Hu \& Bentler, 1999 & $>0.90$ & 0.998 & Acceptable \\
\hline TLI & Hu \& Bentler, 1999 & $>0.90$ & 0.990 & Excellent \\
\hline RFI & Hu \& Bentler, 1999 & $>0.70$ & 0.985 & Excellent \\
\hline
\end{tabular}




\section{FINDINGS}

Based on the analysis of the quantitative data, the following findings are revealed:

\section{QUANTITATIVE STUDY}

1. First, our data establishes a strong correlation between lead user knowledge integration and lead user performance. For design teams who replicate this model, our result indicates that when independent knowledge sources and skills are integrated from a local perspective, the outcome influences implementation outcomes towards an upward trend.

2. Second, contrary to prior literature that herd behavior (human imitation) impacts individual lead user performance, this could not be validated within the frame of the study. Rather, we observed that when herd behavior and lead user performance are mediated by lead user knowledge, integration individual performance increases. We cannot, however, validate that when herd behavior exists in isolation and Lead Users are exhibiting imitative patterns, this increases the chances of performance or implementation outcomes.

TABLE 10

\section{SQUARED MULTIPLE CORRELATIONS: (DEFAULT MODEL)}

\begin{tabular}{|l|r|}
\hline & $\boldsymbol{\beta}$ \\
\hline LUKnowInt & 0.88 \\
\hline LUPerf & 0.771 \\
\hline ImpleOutcome & 0.791 \\
\hline \multicolumn{2}{|l|}{ Squared Multiple Correlations: (Default model) }
\end{tabular}

TABLE 11

HYPOTHESIZED MODEL AND FINAL RESULT

\begin{tabular}{|l|l|l|l|l|l|}
\hline & & & $\boldsymbol{\beta}$ & $\mathbf{P}$ & $\begin{array}{l}\text { Hypothesis } \\
\text { Confirmed }\end{array}$ \\
\hline LUKnowInt & $<---$ & KnowlSharing & 0.487 & $* * *$ & Yes \\
\hline LUKnowInt & $<---$ & SolKnowlImp & 0.444 & $* * *$ & Yes \\
\hline LUKnowInt & $<---$ & HerdBevior & -0.207 & 0.015 & Yes \\
\hline LUPerf & $<---$ & KnowlSharing & 0.229 & 0.019 & Yes \\
\hline ImpleOutcome & $<---$ & SolKnowlImp & 0.332 & $* * *$ & Yes \\
\hline LUPerf & $<---$ & LUKnowInt & 0.749 & $* * *$ & Yes \\
\hline ImpleOutcome & $<---$ & LUKnowInt & 0.582 & $* * *$ & Yes \\
\hline
\end{tabular}


TABLE 12

MEDIATION EFFECT

\begin{tabular}{|c|c|c|c|c|}
\hline Parameter & $\boldsymbol{\beta}$ & Lower & Upper & P \\
\hline LUKnowInt & 0.88 & 0.855 & 0.901 & 0.001 \\
\hline LUPerf & 0.769 & 0.723 & 0.806 & 0.001 \\
\hline ImpleOutcome & 0.794 & 0.75 & 0.828 & 0.001 \\
\hline KnowlSharing & 0.821 & 0.724 & 0.953 & 000 \\
\hline SolKnowlImp & 0.671 & 0.594 & 0.77 & 000 \\
\hline HerdBevior & 0.497 & 0.443 & 0.558 & 000 \\
\hline
\end{tabular}

3. Knowledge Importation and Knowledge Integration strongly influence implementation outcomes. Where both variables are present, our study indicates an upward spiral progression towards successful outcomes. There is a distinct correlation between Lead Users $\rightarrow$ ERP Analysts $\rightarrow$ and knowledge sharing $\rightarrow$ post-implementation performance success as evidence in our structural equation model regression patterns. That Lead Users thrive, survive and succeed where the design team fails is strongly supported by the focused performance of Lead Users, as effectuated by their actions. The actions of these Lead Users are further reflected by first successful implementation outcomes, effective team knowledge, and effective skill reinforcement. In addition, data from our study suggests that Lead Users not only act as unique influentials but also through pivotal siloed performance, influence post-implementation success.

4. Knowledge importation is best utilized within teams by Lead Users who are willing to take responsibility and impact the total outcome of the implementation. Lead Users emerge over time and influence other teams.

\section{IMPLICATIONS ON THEORY AND PRACTICE}

We highlight the following key indicators as relevant implications on research and practice.

1. While design teams focus on traditional approaches like interface modification and customization, there is evidence in the study that Lead Users are utilizing relevant approaches that individual users have mastered over time. Thriving implementation teams are those that ignore siloed relationships for knowledge importation and knowledge sharing. Knowledge importation takes place in both scenarios of less successful and successful patterns. No one scenario is ignored as preferable to the other.

2. The implication on theory is underscored through the rich dimensions of the Theory of Reasoned Action and Planned Behavior, which is measured in the study. Perceived behaviors and subjective attributes effectuate a users performance towards successful imitated outcomes(Banerjee 1992). The prototypes identified in this inquiry are those frameworks linked with user-centered design methods (Lindley, Coulton et al. 2017). Through these designs, we build upon frameworks that could be validated and consistent with sustainable patterns. In other words, these are socio-technical structures that exist but have not been fully explored and tested in the past to validate their impact on both theory and practice, until this research.

\section{QUALITATIVE STUDY}

The following findings emerge from the qualitative section of our study:

1. Knowledge sharing impacts both the learning and dissemination process alike. Lead Users were observed to be cross-checking processes that were ascribed as successful 
before implementing those processes even when some of those steps were documented in work instructions and Job Aides. The validation process was based on the capacity of Lead Users to work successfully against what was deemed difficult to implement. The key issue here was eliminating waste where necessary. There was no evidence that users were skeptical of making errors. However, double checking the process and sharing ideas saved the independent teams of resources that would have been wasted.

2. Where herd behavior was noticeably practiced, there was no evidence that it impacted process flow. This validates our quantitative findings that imitated behavior when applied, did not influence lead user performance. When asked the questions of "How do you view imitating others?" and "How often do you practice herd behavior?", most teams responded in the negative. They affirmed that it is more enjoyable to try new things and fail than trying to imitate others. It was also emphasized that where herd behavior occurs it is done for experimentation in most cases and it ended up being a square peg in a round hole.

\section{DISCUSSION AND CONCLUSION}

Our findings and results indicate a positive trend towards knowledge sharing by Lead Users within ERP Implementations. This goes to substantiate our initial and confirmed hypothesis that knowledge sharing and knowledge integration influence implementations at the micro level. These socio-technical lower-level behavioral patterns significantly influence processes. While these 'border-line' influences may be substantial at some level or incremental at other levels, they have implications that create an impact on both resources and implementation results.

With most firms having a high-cost investment on technical skills that embrace machine learning algorithms and high-end technology that automate systems, little emphasis is put on socio-technical patterns like user skills integration or process and technology rejection. While design teams are focused on leakages in the software and performance issues, the results in our study indicate that human social behavioral patterns influence outcomes in diverse subtle ways.

The findings support the proposed hypotheses. Socio-technical systems address the complexities of technical infrastructure and human-centered frameworks and behavior especially within the ecosystem of ERP implementations. This study represents an important step toward better understanding individual's capacity in utilizing significant tools like herd behavior and knowledge sharing. Although several approaches like adaptation and assimilation have been utilized in the past to capture the effective impact of Lead Users within systems, our study suggests a significant upward move towards better understanding of user behavior tools within successful implementation. In addition, our study gives novel visibility in the form of direct relationship between human behavioral patterns of technical infrastructure within ERP implementation. The findings in the study could be used as a template in impacting design usage and implementation. This unique direction underscores firms with limited resources to focus on the direct effects of rapid knowledge integration that co-habits with knowledge acquisition through derivative practices that re-direct and influence functional systems.

\section{REFERENCES}

Afacan, Y., \& Erbug, C. (2009). An interdisciplinary heuristic evaluation method for universal building design. Journal of Applied Ergonomics, 40, 731-744.

Allie, A. (2017). End User Analysts Innovation within Information Systems - A Post Implementation Impact On Enterprise Resource Planning Systems. A paper presented at the 2018 Decision Science Conference, Washington, DC.

Allie, A. (2017). ERP System Implementation: Lead User Perspective. A paper presented at the 2018 Decision Science Conference, Washington, DC. 
Asprion, P. M., et al. (2018). ERP Systems Towards Digital Transformation. Business Information Systems and Technology 4.0. Springer, 15-29.

Banerjee, A. V. (1992). A simple model of herd behavior. The Quarterly Journal of Economics, 107(3), 797-817.

Carlson, K. D., \& Wu, J. (2012). The illusion of statistical control: Control variable practice in management research. Organizational research methods, 15(3), 413-435.

Cattell, R. B. (1966). The scree test for the number of factors. Multivariate Behavioral Research, 1(2), 245-276.

Gerbing, D. W., \& Anderson, J. C. (1988). An updated paradigm for scale development incorporating unidimensionality and its assessment. Journal of Marketing Research, 186-192.

Hair, J. F., et al. (2010). Multivariate data analysis: A global perspective. Pearson Upper Saddle River, NJ.

Hassan, S. S. (2008). Bringing lead-user innovations to the market: Research and management implications. SAM Advanced Management Journal, 73(4), 51.

Karim, J., et al. (2007). The impact of ERP implementation on business process outcomes: A factor-based study. Journal of Management Information Systems, 24(1), 101-134.

Kearns, G.S., \& Sabherwal, R. (2006). Strategic Alignment between Business and Information Technology: A Knowledge-Based View of Behaviors, Outcome, and Consequences." Journal of Management Information Systems, 23(3): 129-162.

Lai, V. S., et al. (2016). Technology Evaluation and Imitation: Do They Have Differential or Dichotomous Effects on ERP Adoption and Assimilation in China? Journal of Management Information Systems, 33(4), 1209-1251.

Lindley, J., et al. (2017). Implications for adoption. Proceedings of the 2017 CHI Conference on Human Factors in Computing Systems, ACM.

Mun, Y. Y., \& Y. Hwang (2003). Predicting the use of web-based information systems: self-efficacy, enjoyment, learning goal orientation, and the technology acceptance model. International Journal of Human-computer Studies, 59(4), 431-449.

Nikolaeva, R. (2014). Interorganizational imitation heuristics arising from cognitive frames. Journal of Business Research, 67(8), 1758-1765.

Pollock, N., \& Williams, R. (2009). Beyond The ERP Implementation Study: A New Approach To The Study Of Packaged Information Systems: The Biography Of Artifacts Framework.

Rogers, E. M. (2003). Diffusion of innovations. Free Press. New York, 551.

Scholz, R. W., \& Tietje, O. (2002). Embedded case study methods: Integrating quantitative and qualitative knowledge. Sage.

Shao, Z., et al. (2012). The mediating effect of organizational culture and knowledge sharing on transformational leadership and Enterprise Resource Planning systems success: An empirical study in China. Computers in Human Behavior, 28(6), 2400-2413.

Simon, H. A. (1972). Theories of bounded rationality. Decision and Organization, 1(1), 161-176.

Von Hippel, E. (1986). Lead Users: a source of novel product concepts. Management Science, 32(7), 791805.

Yin, R. K. (2003). Case study research: design and methods, Applied social research methods series. Thousand Oaks, CA: Sage Publications, Inc.

Younous, E., et al. (2018). Critical Success Factors to Implement Enterprise Resource Planning in Morocco Large Companies' Case Study. American Scientific Research Journal for Engineering, Technology, and Sciences (ASRJETS), 39(1), 159-168. 